\title{
ISOLAMENTO OU COLABORAÇÃO: PERCURSOS, TRÁFEGOS E CAMINHOS NA EDUCAÇÃO A DISTÂNCIA
}

\author{
Ana Maria Cardoso | ana.mcardoso@aedu.com \\ Doutorado em Literatura Brasileira pela Universidade Federal do Rio Grande do Sul. \\ Nivaldo Carleto | nivaldo.carleto@aedu.com \\ Doutorado em Educação Escolar pela Universidade Estadual Paulista Júlio de Mesquita Filho. \\ Maria Salete Genovez | maria.genovez@aedu.com \\ Doutorado em Educação pela Universidade Estadual Paulista Júlio de Mesquita Filho.
}

Silvia Cristina Martini Rodrigues | silvia.rodrigues1@aedu.com

Doutorado em Engenharia Elétrica pela Universidade de São Paulo.

\section{Resumo}

As novas tecnologias de informação e comunicação promovem inúmeras mudanças no comportamento social e cultural em nossos dias. O que se sabe é que o impacto desse fenômeno repercute em diversos segmentos sociais, mas é na forma de comunicação e na educação que esses fatores ganham força. Aliás, é o modo como o sujeito do século XXI se expressa que define uma inegável quebra de paradigmas. Se as gerações anteriores estavam acostumadas a assistir a programas televisivos quase sempre relacionados à aplicabilidade e venda de um produto, agora a geração dos nativos digitais interage nas redes sociais via web redefinindo posturas. O presente artigo reflete sobre os condicionamentos impostos ao telespectador para, num segundo momento, discutir de que maneira as novas ferramentas de TIC podem contribuir para uma dinâmica aprendizagem em rede. Nessa perspectiva, fez-se um estudo de autores que discutem a Educação a Distância, a fim de procurar compreender em que medida os estudantes têm se servido dos meios disponíveis para a interação em rede e no ambiente de aprendizagem online. O que se observa, no entanto, é que o aprendiz ainda não consegue utilizar as ferramentas disponíveis nos espaços de interação, o que indica ser este um dos obstáculos para o aprendizado em rede. É possível dizer que essa postura está relacionada a lacunas de formação do aprendiz pelo não exercício da autodisciplina e da autonomia, o que ocasiona, possivelmente, um sentimento de isolamento. Essa sensação de não pertencimento, infelizmente, tem contribuído para os elevados índices de evasão no ambiente de Educação a Distância.

\section{Palavras-chave}

Educao a Distncia. Mdias. Literatura brasileira 


\section{Isolation or collaboration: paths, traffic and ways in distance education.}

\section{Abstract}

The new Information and Communication Technologies promote many changes in the social and cultural behavior nowadays. What is known is that the impact of this phenomenon reflects in many social sectors, but it is in the form of communication and education that these factors are gaining strength. In fact, the way the individual of the XXI Century makes use of and expresses himself through these instruments may define an undeniable shift in paradigm. If previous generations were accustomed to watching television programs almost always related to the applicability and selling of a product or to the determination of behavior, now, the interaction through the internet and social networking redefines postures. This article reflects the constraints imposed on the viewer through a tale of Frei Betto, so, second, discusses how the new tools of ICT can contribute to a dynamic network learning. In this perspective, we tried to make a bibliographical survey of scientific papers dealing with the subject in question and to understand the extent to which students have made use of the resources available for networking and interaction in online learning environment. What occurs, however, is that learners cannot yet empower themselves with the spaces of interaction that are at their disposal, such as forums, chats, emails, indicating that this is an obstacle to bind to the course. The misuse of language and lack of a sense of belonging, unfortunately, have contributed for the students to still feel reluctant or lost in the distance education environment.

\section{Keywords}

Distance education. Media. Brazilian literature.

\section{Considerações Iniciais}

As novas tecnologias de informação suscitam profundas mudanças socioculturais que a sociedade ainda não tem condições de compreender em sua totalidade. Sempre que se modificam aspectos sociais surgem resistências, pois ainda não se tem clareza do seu impacto e, ao mesmo tempo, é difícil avaliar como essas transformações se perpetuarão. Os olhares apontam para as mudanças em torno do uso da linguagem e do ensino a partir do uso das tecnologias de informação e comunicação (TIC) nos dias de hoje.

Por meio das redes sociais, nota-se que a comunicabilidade em rede deu oportunidade para que o conteúdo prepondere em detrimento da linguagem. As atuais práticas de comunicação fazem com que a oralidade prevaleça diante da escrita, apesar de as instituições de ensino demarcarem claras distinções entre língua falada e língua escrita. Frente às práticas cotidianas, os textos produzidos em sala de aula trazem em si cada vez mais mesclas de oralidade, o que originou a definição comumente utilizada como internetês.

Os professores veem a nova situação com perplexidade e, desse modo, se faz necessário refletir sobre essas mudanças na produção de textos dos estudantes. Isso porque os usuários em rede utilizam a linguagem intensamente e se comunicam numa velocidade nunca antes vista. Assim, a formalidade da língua padrão anunciada pelos arautos das academias de letras não é um limite para os usuários em rede. Eles se comunicam, trocam, se divertem e se relacionam em meio à avalanche de situações comunicacionais que se define, segundo Castell, como Sociedade da Informação.

As redes sociais de Facebook, Orkut, MSN, entre outras, promovem dia a dia formas de interação que encantam pela diversidade de informações em múltiplas linguagens: visual, sonora, interativa. Crianças e adolescentes envolvidos com esses novos instrumentos tendem a resistir à escola, pois os clássicos paradigmas de ensino não os desafiam mais. É possível dizer, inclusive, que as instituições de ensino são vistas com certa desconfiança, principalmente pelos estudantes 
universitários, pois estes percebem que os profissionais reconhecidos no mercado de trabalho precisam utilizar as TIC. Nessas condições, o modelo de escola que repassa conteúdos e os avalia por meio de exercícios distantes do cotidiano cai em descaso frente ao olhar dos jovens do século XXI. Eles desejam incorporar os meios audiovisuais em suas práticas estudantis e a gama de riquezas que as tecnologias da informação apresentam. Afinal, os jovens normalmente já as utilizam no seu cotidiano com eficácia e encantamento.

Assim, o interesse das gerações nascidas a partir dos anos 1980 vai além da mera assimilação de conteúdos, pois elas querem dialogar e, de preferência, recriar, experimentar outras linguagens diante do que aprendem. O conceito de "nativos digitais" (BELLONI, 1999) define essa geração com muita propriedade, pois, frente à dos "imigrantes digitais", eles possuem habilidades e competências para o uso das novas ferramentas e ainda interagem no ambiente em rede com extrema familiaridade. Daí o compartilhamento de informações ter se tornado uma marca dos novos tempos da web, em que os jovens procuram e desejam criar juntos, muito próximo do que Pierre Lévy (1999) definiu como inteligência coletiva. Nesse tráfego de informações se nota um interesse muito expressivo em agregar pessoas em torno de causas sociais, como na defesa do meio ambiente ou na autoafirmação de grupos excluídos socialmente, como mulheres, negros, gays. No entanto, na rede de informações existem muitos desafios a serem desvendados, pois, se por um lado ela exerce grande fascínio, por outro seus caminhos podem ser nebulosos em igual medida.

Este artigo pretende tratar da mudança de paradigmas que se opera com base na interação com as tecnologias de informação e comunicação e procura ainda refletir acerca do impacto dessa postura frente à Educação a Distância. Para tanto, a narrativa curta de O telespectador, de Frei Betto, se torna uma referência significativa com vistas a refletir sobre o modo de interação com a programação televisiva, principal meio de comunicação de massa, para, adiante, discutir as mudanças que surgem com a internet, especialmente no que se refere à educação e à linguagem. Este traba- lho visa fazer esse percurso, a fim de mapear a postura dos sujeitos no tráfego em rede.

\section{O olhar televisivo}

A partir dos anos 1970, as gerações cresceram em frente a um aparelho de TV, deixando-se seduzir, desde o início, por um universo de imagens e narrativas que seguiu encantando adultos, crianças e adolescentes ao longo dos anos. O veículo alcançou grande popularidade, instalando-se triunfante na maior parte dos lares, inclusive nos locais mais distantes. O que se sabe é que a televisão exerceu uma influência importante na formação cultural dos brasileiros, como foi o rádio e o cinema para as gerações antecessoras.

A imposição do silêncio, pelas rígidas leis da censura no período ditatorial, dominou o país por vinte anos e deixou marcas profundas em nossa formação social e cultural ${ }^{1}$. Diante disso, a televisão se tornou o principal veículo a divulgar a ideologia dominante nos anos de chumbo, que, em paralelo com a restrição da liberdade política, estimulou a formação de consumidores. Em outras palavras, o período ditatorial obteve nos meios de comunicação de massa um forte aliado na divulgação de suas ideias e, ao mesmo tempo, uma ferramenta para o estímulo do desenvolvimento econômico e abertura ao mercado internacional. Outro fator que somou esforços para essas mudanças foi o êxodo do meio rural, que ampliou a presença da televisão nas cidades, tornando-a o meio mais utilizado para o entretenimento. Há que se considerar ainda a violência das metrópoles, que, por conta de um jornalismo cada vez mais sensacionalista, fez com que a população se fechasse em si mesma nos seus apartamentos e lares, isolados uns dos outros, tendo a televisão como seu principal interlocutor.

1 O período da ditadura no contexto brasileiro promoveu inúmeras mudanças na cultura e na sociedade; a produção cultural, sobretudo a literatura, modificou a sua expressão de linguagem em razão da imposição do silêncio e da violência do sistema político. Cf. CARDOSO, Ana Maria. In: Sonho e transgressão em Caio Fernando Abreu: o entre-lugar de cartas e contos. Tese de Doutorado, UFRGS, 2007. 
É desafiador que gerações acostumadas a assistir a programas televisivos quase sempre relacionados à aplicabilidade e venda de um produto ou à disseminação de determinados comportamentos se vejam agora diante de novas formas de interação promovidas, sobretudo pela internet ao longo das últimas décadas. Frei Betto refletirá acerca da incorporação desse traço cultural no perfil do telespectador. Aliás, a coletânea acentua o destino dos indivíduos frente às sombrias imposições da indústria cultural, análogas ao que será conceituado como Inferno, e questiona as mudanças culturais resultantes da recepção da televisão, veículo popular no contexto brasileiro. Viriato, protagonista de O telespectador, habituado a uma vida de indiferença e devassidão, se vê diante do pós-morte e intui que seu comportamento pouco virtuoso não lhe permitiria galgar espaços elevados perante o Criador.

A narrativa inicia no momento em que Viriato é conduzido ao local onde pagará a sua pena. Depara-se, contudo, com uma sala clara e asséptica, que possuía apenas uma cadeira e um televisor, no mais completo isolamento. $\mathrm{O}$ fato de o sujeito estar num ambiente excessivamente limpo, como num hospital, é simbólico, porque ali não lhe é possível trazer as marcas que definem a sua identidade. O protagonista, nesse caso, é desprovido de cultura, pois não trouxe consigo a bagagem de suas vivências, e seus laços de afeto são, ao que parece, praticamente inexistentes. Apreensivo num primeiro momento com a possibilidade de um total isolamento e solidão, minutos depois ele vibra diante do que lhe é oferecido: uma rede infinita de canais disponíveis. Contudo, foram-lhe impostas determinadas condições: ele deveria estar à frente da televisão durante 24 horas, sem interrupção, sequer para dormir ou se alimentar; era-lhe impossível desligá-la ou baixar o volume ad aeternum.

Assim que seu anfitrião se retira, ele tenta ir à porta, mas descobre que está preso à poltrona. Ele se coisificou, tal como o móvel da sala. No entanto, ele não se abala com a situação, o que sugere que o papel que lhe fora imposto não era uma novidade. O universo ficcional traça o perfil dos sujeitos metropolitanos, que, isolados, preenchem suas angústias com programas televisivos, pois as trocas com os demais não despertam interesse; ele que, ao que parece, condicionou-se ao papel de mero consumidor de imagens e ideias preestabelecidas. A indiferença ou embotamento dos sentidos define sua personalidade, o que faz com que ele se torne uma presa fácil para o consumo. Ele confunde sentimentos e desejos, pois tem os olhos vendados pela ilusão:

\begin{abstract}
ele tinha ânsias de consumo e, no entanto, estava impedido de acesso ao mercado. E seu desejo desenrolava-se como um fio infinito. Seria menos doloroso se a sua autoestima não estivesse sendo minada dia a dia. Não possuir aqueles produtos que conferiam valor a seus proprietários acarretava-lhe um sofrimento que lhe parecia sempre insuportável. Sentia-se faminto diante de um banquete, mas com a boca irremediavelmente costurada (BETTO, 2000, p. 114).
\end{abstract}

No entanto, após o período de três meses de encarceramento e total servidão ao que o aparelho lhe impunha, Viriato percebe que a TV não era uma mera transmissora de atrativos, mas se tornava um "ente real" que pensava por ele, sonhava por ele, imaginava por ele; em suma, sentia-se completamente esvaziado em sua identidade. O longo tempo exposto à mídia televisiva e à série de programas intercalados não lhe permitia pensar sobre o que estava sendo apreciado. Ele sente-se exaurido, pois a força da criatividade, das trocas, dos diálogos havia sido suprimida por meras cópias e reproduções acabadas. O próprio nome da personagem, visualmente, sugere a coisificação do ser, já que se origina do verbo transitivo direto ver, ou ser espectador, testemunha. O tempo, para Viriato, tornava-se um só, "já não havia passado, presente ou futuro", e o espaço subjetivo do telespectador tinha se esgotado em razão de um excesso de imagens, fragmentos de ideias e assuntos diversos. $\mathrm{O}$ encarcerado finalmente compreende a intensidade da penalidade que lhe fora imposta, pois se sentia "asfixiado por aquela profusão de signos que roubavam a palavra e sonegavam o silêncio, dilacerando-o interiormente". 
As possibilidades de extravasar pelo consumo não lhe são permitidas, em razão da sua condição de isolamento. Aqui a angústia acompanha o indivíduo que, apesar dos inúmeros estímulos midiáticos, não consegue sanar sua ambição desmedida. Subjulgado, ele se torna objeto, e a televisão ganha força e autonomia, pois essa é a influência nefasta que a programação televisiva pode lhe oferecer. A capacidade de nomear, que define os sujeitos, lhe foi negada. Ele se tornou um sujeito raso, reificado. O embrutecimento dos sentimentos é estimulado, a fim de não sentir empatia pelos demais, sobretudo por aqueles que não estão dentro do que se considera o padrão de comportamento social:

a programação saturava-o. Embora variada, obedecia aos mesmos modelos repetitivos. A beleza esguia das mulheres, a ridicularização dos homossexuais e dos gordos, a apologia ao adultério, a comicidade derivada da desgraça alheia, a prosperidade como fruto da sorte, a espetacularização da notícia, a nova embalagem de velhas piadas, velhas histórias e velhas imagens (BETTO, 2000, p. 114).

É significativo que o sujeito isolado encontre uma forma de relaxar nos programas de entretenimento, mas, à medida que o tempo passa, o quadro se torna aprisionador. Se não há interação com o outro, as forças de autonomia e liberdade se esvaziam, pois a construção da identidade precisa ocorrer pela via dos diálogos, das trocas afetivas. A palavra permite a expressão do pensamento e da subjetividade, definindo a identidade cultural dos sujeitos. Aqui o sombrio prevalece, análogo ao Inferno, que o antropólogo Frei Betto pretende fazer o leitor questionar.

Outro aspecto relevante é o fato de o veículo televisivo ser uma forma de entretenimento, sobretudo para os que se encontram isolados: os detentos, os aprisionados e os que, diante da falta de políticas públicas, como as crianças e idosos, não possuem atividades para além dos limites de seus lares (MININNI, 2008). A formação cultural das mídias é um tema complexo, que exige um debate mais amplo e democrático, pois considerar os valores éticos e humanos é de fundamental interesse para viver em sociedade.

\section{Interatividade e ensino a distância}

Superar a postura passiva do telespectador, a fim de se apropriar das novas ferramentas de TIC, como a internet, por exemplo, é realmente um salto para outra margem, um desafio para os sujeitos do século XXI. As pesquisas indicam crescimento na modalidade Educação a Distância, e o formato metodológico e teórico de ensino presencial não pode apenas ser transferido para o ensino a distância por meio das novas ferramentas. Exige-se cuidado na preparação do material, no sentido de atentar para as particularidades dos educandos e, assim, contextualizar os conhecimentos na região em que o aluno se situa.

Em 2007, o governo decidiu estabelecer referenciais de qualidade para regulamentar os cursos a distância, a fim de minimizar os efeitos muitas vezes insatisfatórios dessa modalidade de ensino, porque, a EaD se encontra num momento de plena expansão no Brasil. Um dos aspectos enfatizados é o de que um projeto de curso superior a distância precisa estar atento a um forte compromisso institucional com vistas a garantir a formação técnico-científica para o mundo do trabalho e, concomitantemente, considerar a dimensão política para a formação do cidadão. $\mathrm{E}$ mais: a educação superior - seja ela presencial ou a distância, nas suas inúmeras combinações entre presencial, presença virtual e a distância - deve enfatizar o desenvolvimento humano, a fim de se responsabilizar com a construção de uma sociedade mais justa, ética e igualitária.

Outro aspecto importante desse documento é que a Educação deve superar a visão fragmentada do conhecimento, a fim de compor a estruturação curricular por meio da interdisciplinaridade e da contextualização. Nessa perspectiva, a Educação encontra um espaço desafiador e distinto dos meios de comunicação de massa, como o veículo televisivo, por exemplo. Se a televisão conta com um aparato voltado ao consumo e à padronização do pensamento, o arcabouço teórico e prático dos cursos de Educação a Distância deveria ter um percurso que fosse ao sentido oposto, já que deve instigar questionamentos, práticas e discursos inovadores para que ocorra o despertar da criatividade, autonomia e cidadania. 
Nesse sentido, a Educação a Distância precisa se constituir de um ambiente de interação dos alunos entre si, por meio de fóruns e chats, e deles com o professor; consequentemente, com a apreensão do conhecimento disponibilizado de forma autônoma. Para tanto, é necessário destacar as diferenças entre interação e interatividade, que, muitas vezes se expressam de maneira difusa. Para Belloni (1999), o conceito sociológico de interação é a ação recíproca entre dois ou mais atores, em que ocorre intersubjetividade, isto é, o encontro entre dois sujeitos que pode ser mediado por algum veículo técnico de comunicação (telefone ou carta). Interatividade é a potencialidade técnica que é disponibilizada por um determinado meio, como no hipertexto ou nos jogos eletrônicos; há também o conceito de interatividade como a atividade humana que age sobre a máquina e recebe em troca uma "retroação".

Diante dos novos modelos de interatividade, é inevitável que o papel do professor também se modifique nessa quebra de paradigmas. $\mathrm{O}$ novo formato exige que o professor se torne um mediador do conhecimento e sua função se dissolva hierarquicamente em relação aos encontros clássicos que se davam em sala de aula. Antes, a aprendizagem ocorria, na maioria das vezes, pelo seu referencial teórico e, a partir daí, ocorriam trocas, diálogos, enfim, o saber. Nos dias atuais, os docentes, mediadores em um novo espaço de conhecimento, não são os únicos referentes na aprendizagem; aliás, percebe-se que essas mudanças também se estenderam ao ensino presencial. Estudos demonstram que os professores, sempre atentos aos objetivos propostos pela disciplina, devem recorrer às múltiplas linguagens a fim de diversificar a apreensão dos conteúdos e ir ao encontro do universo sociocultural dos seus educandos. $\mathrm{Na}$ atual quebra de paradigmas hierárquicos, o professor também é um aprendiz das linguagens visuais, sonoras, interacionais, e cabe também a ele a autoaprendizagem, inevitável ao novo contexto educacional.

Enfatiza-se, neste caso, a necessidade do letramento digital como instrumento de inclusão social. Vale dizer que incluir digitalmente não significa apenas "alfabetizar" a pessoa em informática, mas também melhorar os quadros sociais a partir do manuseio dos com- putadores. Naturalmente que, para que isso ocorra, é necessário que o indivíduo seja letrado no seu idioma e que tenha certo domínio quanto aos códigos de leitura e escrita vigentes para que, a partir daí, possa aproveitar as possibilidades que as TIC oferecem. Isso não é diferente no cotidiano dos professores, que necessitam não só dominar as tecnologias de informação e comunicação como também reorganizar como irão disponibilizar os conteúdos e saberes para uma aprendizagem mais efetiva e próxima dos seus educandos.

Assim, as transformações originárias do uso das TIC na educação são inúmeras e acontecem em inúmeras direções. $\mathrm{O}$ uso das redes sociais como prática de interação social tem ganhado amplo número de adeptos. Contudo, a transposição da prática para o ambiente da aprendizagem não conquista a mesma adesão $e$ eficácia. Pesquisas demonstram que os alunos de Educação a Distância ainda não conseguem se apropriar das formas interativas que lhes são disponibilizadas. Os ambientes virtuais de ensino - fóruns, salas de bate-papo, e-mails ainda são utilizados de forma pouco representativa, o que faz com que o aprendiz não se sinta integrado ao curso do qual faz parte. Esse fator é um dos determinantes para a evasão dos cursos na modalidade a distância, conforme Serra (2005). A nova regulamentação do Ministério da Educação (2007) atentou para a referida problemática e definiu que cursos online precisam dar ênfase às trocas de saberes por meio de fóruns e salas de bate papo, pois compreendem que são formas de convivência necessárias ao aluno e contribuem na apreensão do conteúdo. Cabe ressaltar que esses instrumentos minimizam a sensação de isolamento, uma vez que os aprendizes trocam com os colegas, com o professor; em suma, partilham o conhecimento com um grupo. Nesse caso, não ocorre distinção entre a sala presencial e a virtual.

Outro aspecto a considerar como obstáculo à interatividade, em especial ao eixo comunicativo (SERRA, 2005), diz respeito à dificuldade de expressão escrita que inevitavelmente acompanha os alunos, seja no ensino a distância ou no presencial. As mensagens tendem a apresentar enunciados de duplo sentido ou confusos, impedindo uma maior eficácia na resolução de proble- 
mas pelo professor/tutor na aprendizagem do ensino on$\operatorname{line}^{2}$. Há que se considerar ainda que, no turbilhão de informações encontradas na rede, os alunos têm dificuldades de pesquisar um determinado assunto, pois não distinguem o grau de relevância de um texto para outro ou a confiabilidade dos endereços de pesquisa. Aqui se encontram competências indispensáveis ao saber e que se desenvolvem ao longo da prática de aprendizagem, seja ela a distância ou no ensino presencial.

Os cursos também precisam considerar o acesso aos meios tecnológicos para seus educandos: bibliotecas, laboratórios, videotecas, entre outros. Além disso, a Educação, sobretudo na modalidade a distância, precisa contemplar cursos de caráter introdutório, a fim de sanar dúvidas quanto à alfabetização digital e para que seus estudantes tenham sucesso. Aliás, esse programa contribuirá para o seu desempenho e habilidade não apenas no curso do qual fazem parte, mas também no exercício de uma plena cidadania. E, por fim, é inegável que o material a ser disponibilizado deve ser pensado e articulado por uma equipe multidisciplinar para que o ambiente de ensino-aprendizagem seja atrativo, com vistas a diminuir o crescente abismo que separa a escola da sociedade.

\section{Interatividade: nativos e imigrantes digitais}

Se as tecnologias de informação e comunicação ganham cada vez mais força no cotidiano dos indivíduos, quais são os possíveis caminhos para o exercício da interação? Conforme discutido anteriormente, os pressupostos da Educação a Distância esbarram em problemáticas que estão inscritas no bojo das questões sociais, culturais e políticas de nosso tempo. Discutir a Educação a Distância é discutir também a educação presencial e, por extensão, a formação dos sujeitos numa perspectiva apoiada nos valores humanos, na ética, na cidadania.

2 A autora faz um estudo detalhado de como ocorre a interação comunicacional entre professores e alunos, a fim de verificar quais são os impedimentos de aprendizagem no ambiente online. Cf. SERRA, Daniela Tereza Santos. Afetividade, aprendizagem e educação online. Dissertação de Mestrado, Belo Horizonte, PUCMINAS, 2005
Repensar a Educação na modalidade a distância é também refletir acerca das instituições de ensino que não podem mais pensar na mera transferência de conteúdo, pois correm o risco de se voltar ao ensino clássico, no qual existia espaço apenas para ouvir, anotar e repetir. Da mesma forma, o aprendizado com as tecnologias da informação precisa encorajar o aluno a apreender o conhecimento de forma criativa, contextualizada e, de preferência, exercitá-lo na sua capacidade de se envolver com seus pares, de compreender e tentar resolver problemas sociais e culturais inscritos na sua escola, no seu bairro, cidade.

Outro desafio é o ensino técnico-científico, que instiga o aprendizado muitas vezes apenas para o mundo do trabalho. Nessa perspectiva, os cursos são uma imersão em conteúdos, provas, trabalhos que consideram o desenvolvimento quantitativo e, inevitavelmente, competitivo. Assim, os educandos saem desses cursos para competir no mercado de trabalho com vistas a encontrar um espaço de atuação que se valha sobretudo de possibilidades de consumo e status quo. Não considera, assim, o ensino como aprimoramento integral do indivíduo, no sentido de formá-lo para o trabalho, mas também para uma vida em sociedade com autonomia, consciência reflexiva, cidadania, ética e disposição para a colaboração e cooperação junto aos demais indivíduos.

Se pensar a Educação é rever valores sociais, culturais e políticos, com o ambiente em rede não é diferente. Faz poucas décadas que a internet se tornou presente nos lares dos indivíduos e, consequentemente, no universo escolar e profissional. No entanto, já é possível constatar o abismo que separa os cidadãos letrados digitalmente dos não letrados. Outro aspecto a considerar é o de que as últimas gerações interagem, desde o princípio do aprendizado, no universo online: a geração dos nativos digitais (BELLONI, 1999). Já os imigrantes digitais veem esses meios de forma, no mínimo, diferente da outra; afinal, para essas gerações antecessoras o universo online não é um território familiar, isto é, esse grupo apenas migra para o ambiente em rede, mas não tem o mesmo sentimento de pertencimento que os nativos digitais. A disparida- 
de ocorre desde o ambiente familiar, no qual os pais, cada vez mais assoberbados de tarefas, seja no âmbito privado ou profissional, perdem espaço de convivência com seus filhos, pela maciça presença das tecnologias de informação e comunicação em suas casas. Diferentemente do uso da televisão, nos últimos anos os nativos digitais têm maiores habilidades no uso das tecnologias do que a geração de seus pais, o que faz com que a mediação do adulto em relação às crianças seja minimizada, às vezes, pela sua ignorância frente ao assunto. Cabe dizer que, nessa mesma direção, uma grande parcela dos docentes que se encontra em sala de aula também faz parte do grupo dos imigrantes digitais. Nessas condições, o afastamento entre gerações, em nossos dias, se torna praticamente inevitável.

Por fim, sabe-se que as formas de socialização que ocorrem em meio ao ambiente em rede ainda são uma novidade para grande parcela da população. É necessário um debate mais amplo em torno de políticas públicas, no contexto brasileiro, para que haja democratização do acesso à rede, já que isso não se efetivou plenamente. Outra questão é que, em alguns casos, a má qualidade técnica dos serviços da internet ainda dificulta a operacionalização do seu uso. Na mesma direção, encontram-se os estímulos legais que permitirão à população o uso da TV digital e os recursos interativos a favor dessas mudanças. $\mathrm{O}$ acesso às tecnologias de informação e comunicação e um uso consciente dessa ferramenta poderá, inclusive, fortalecer laços entre as gerações, uma vez que, hoje, se nota certo distanciamento entre os que vivenciam o aprendizado com essas ferramentas desde o início do processo da aprendizagem, os "nativos digitais", e os que não contaram com a referida estrutura.

\section{Considerações finais}

O uso das tecnologias de comunicação $e$ informação, sobretudo a internet, contribui para a criação de um espaço favorável à democratização do saber $e$ o seu livre fluxo. $\mathrm{O}$ conhecimento não se restringe mais a um grupo, é compartilhado por um amplo número de indivíduos, independente do local onde é produzido. As distâncias, por sua vez, minimizadas pelo ambiente em rede, promovem trocas colaborativas, criativas e autônomas. A escola e a família, principais referentes de conhecimento, não podem voltar as costas às inevitáveis mudanças em sociedade, mas defender $e$ fortalecer os valores humanos e éticos, indispensáveis a um convívio social mais harmônico. Dessa maneira, o abismo que separa a geração dos letrados no ambiente digital da dos não letrados deve ser paulatinamente resolvida. Em paralelo, o último grupo pode contribuir pelo diálogo, pelo comprometimento e pelo afeto, condições tão necessárias à sociedade.

Nessa perspectiva, é preciso considerar a influência da indústria cultural na formação dos brasileiros, sobretudo a da mídia televisiva, que condiciona comportamentos há muitas décadas. A partir daí, não basta apenas o acesso irrestrito às tecnologias; é preciso preparar os indivíduos, tanto na qualidade da sua formação cultural, em especial no domínio do código escrito, quanto no exercício de uma postura ética, responsável e colaborativa em relação aos ambientes em rede. Enfim, as bases à democratização do ensino, seja ela presencial ou a distância, ainda estão em vias de se estruturar, pois são inúmeros os fatores que envolvem a aprendizagem nos dias atuais.

\section{Referências}

BELLONI, M. L.. Educação a distância. São Paulo: Autores Associados, 1999.

BETTO, Frei. Treze contos diabólicos (e um angélico). São Paulo: Planeta, 2005.

CARDOSO, Ana M. Sonho e transgressão em Caio Fernando Abreu: o entre-lugar de cartas e contos. Tese de doutorado. UFRGS, 2007.

CASTELL, Manuel. A era da informação: economia, sociedade e cultura. Vol. 2. São Paulo: Paz e Terra, 2010.

LÉVY, Pierre. Cibercultura. São Paulo: Ed. 34, 1999. 
O que é virtual? São Paulo: Ed 34,1996.

MARTINS, Cátia Alves \& GIRAFFA, Lúcia M. Martins. Formação do docente imigrante digital para atuar com nativos digitais no ensino fundamental. In: VIII Congresso Nacional de Educação da PUCPR (EDUCERE), Curitiba, 6 a 9 de outubro de 2008.

MININNI, Giuseppe. Psicologia cultural da mídia. São Paulo: Girafa; Ed SESC, 2008.

MINISTÉRIO DA EDUCAÇÃO. SEED. Referenciais de qualidade para Educação Superior a Distância. Brasília, agosto de 2007. Disponível em: http://portal.mec.gov.br/seed/arquivos/pdf/legislacao/refead1.pdf

MONTEIRO, Elis. Nativos digitais já estão dominando o mundo e transformando a forma como o ser humano se comunica. O Globo - Revista Digital, publicado em 18/05/2009, disponível em http://oglobo.globo.com/ tecnologia, acesso em 12 de agosto de 2012.

MORAES, Heloisa J. P. Inteligência coletiva: o ciberespaço como retrato da sociedade... In: Revista Famecos, Porto Alegre, v.18, n. 2, p 542-556 maio de 2011.

PASSOS, Paula Caroline Schifino Jardim; BEHAR, Patricia Alejandra. Interação e Interatividade através das interfaces de materiais educacionais digitais. Revista Renote, v. 9, n. 1 jul. 2011.

SANTOS, Daniela Gehlen dos; GOMES, Andreia. Considerações acerca do Internetês. Ensino \& Pesquisa, União da Vitória, v. 1, n. 5, 2008.

SERRA, Daniela Tereza Santos. Afetividade, aprendizagem e educação online. Dissertação de mestrado, Belo Horizonte, PUCMINAS, 2005

VELOSO, Renato. Tecnologias da informação e comunicação: desafios e perspectivas. São Paulo: Saraiva, 2012. 